www.nature.com/ja

\title{
EDITORIAL
}

\section{A new partnership between the Society for Actinomycetes Japan and The Journal of Antibiotics: a message from the SAJ president}

The Journal of Antibiotics (2011) 64, 287; doi:10.1038/ja.2011.19

$\mathrm{T}$ he Society for Actinomycetes Japan (SAJ) has entered into a new and exciting partnership with The Journal of Antibiotics (JA), with the agreement of the Japan Antibiotics Research Association (JARA) and the Editorial Board of JA. This new endeavor offers great promise for the future and I would like to express my deepest gratitude to all associations and persons who have helped to accomplish this goal.

The SAJ first started as an informal community of actinomycetologists in Japan, called 'Housenkin-Danwakai' in 1955. In 1985, based on this community, the SAJ was established and recognized as a registered academic research organization by the Science Council of Japan. In the 55 years since its foundation, the society has been a center of active and extensive research, study, education and training activities of Japanese actinomycetologists. In addition to annual meetings and regularly held colloquia, the SAJ publishes its official journal 'Actinomycetologica', in which many papers concerning taxonomy, ecology, isolation methods, metabolites, biochemistry and related topics of actinomycetes are published.

Based on the long-standing history and achievements over the last 55 years, the SAJ decided to take the next step and approach JARA to partner with JA, and make it the SAJ's new, official English-language journal. This was a carefully considered decision. It was clear that the aims and ambitions of the SAJ and JA were closely aligned, which led to a long-standing friendship between the two organizations. Indeed, many papers from SAJ members were and are contributed to JA. A partnership was an attractive proposition, and the SAJ had long considered the best way to collaborate with JA. The recent decision by
JA to add a new section on Taxonomy and Ecology aligned the Journal's scope to 'Actinomycetologica. This was an opportunity to extend our collaboration and led us to decide to make this important partnership with JA and make it the primary and official journal of the SAJ, while 'Actinomycetologica' continues to exist as the SAJ's official newsletter.

We believe this partnership will bring many advantages and benefits to both JA and the SAJ, and will optimize the power and impact of JA in the community of antibiotics and actinomycetes researchers in Japan and abroad. As an official partner of the journal, we are very pleased that we can help the Journal's editorial and peer-review process by providing a Section Editor for the new Taxonomy and Ecology section. The SAJ will also provide editorial board members, and help other Section Editors evaluate taxonomical issues of submitted manuscripts.

I firmly believe that this new partnership will further promote scientific development and innovation in actinomycetes research. I would therefore encourage all members of SAJ and actinomycetologists around the world to actively support this collaboration as active contributors and enthusiastic readers of our new official journal, The Journal of Antibiotics.

Yōko Takahashi

President, The Society for Actinomycetes Japan Kitasato Institute for Life Sciences, Kitasato University, Tokyo, Japan E-mail: ytakaha@lisci.kitasato-u.ac.jp 